\title{
CAST: An Online Tool for Facilitating Local Involvement in Watershed Implementation Plans for the Chesapeake Bay Total Maximum Daily Load
}

\author{
Olivia H. Devereux and Jessica R. Rigelman
}

\begin{abstract}
The Chesapeake Assessment Scenario Tool (CAST) is an online nutrient and sediment load estimator to streamline and facilitate pollutant control plans consistent with the 2010 Chesapeake Bay total maximum daily load (Bay TMDL). CAST simplifies the process for building scenarios and provides estimates of nitrogen, phosphorus and sediment load reductions using best management practices. CAST uses the same data as was used to establish the Bay TMDL. Load reduction calculations are designed to allow rapid online scenario development while keeping the load estimations within $1 \%$ of the Watershed Model's urban loads. Because CAST is online and easy to use, local jurisdictions may deeply engage, thereby improving local management decisions and securing a higher likelihood of implementation.
\end{abstract}

Keywords: TMDL, phosphorus, nitrogen, CAST, water quality.

\section{Introduction}

In 2010 the USEPA implemented a total maximum daily load (TMDL) for nitrogen, phosphorus and sediment for the entire Chesapeake Bay watershed (USEPA 2010). The Bay watershed is approximately $64000 \mathrm{mi}^{2}\left(165760 \mathrm{~km}^{2}\right)$ and includes seven major jurisdictions: New York, Pennsylvania, West Virginia, Maryland, Delaware, District of Columbia and Virginia (Figure 1). The USEPA issued one overall Bay TMDL with bay watershed limits of $185900000 \mathrm{lb}(84500 \mathrm{t})$ nitrogen, $12500000 \mathrm{lb}(511364 \mathrm{t}$ ) phosphorus, and $6450000000 \mathrm{lb}$ (2931818 t) sediment each year. These limits are further divided by jurisdiction and major river basin since each jurisdiction has unique policies, politics and geography that drive how the reductions will be met. The USEPA requires that each jurisdiction develop a watershed implementation plan (WIP) and milestones for effecting those plans (USEPA 2011).

WIPs specify the best management practices (BMPs) to be implemented within each jurisdiction, along with the location of these BMPs. These plans must meet the allocations for the pollutant source sector. Since planning happens at a more local scale (such as the county), jurisdictions downscaled the allocations to the county level and asked the local county governments to each develop a county plan. Local jurisdictions are required to submit multiple plans and annual implementation of best management practices to indicate they are reaching goals under the Bay TMDL.

The Chesapeake Bay Program's Watershed Model-Hydrological Simulation Program-Fortran (Watershed Model) was used by the USEPA to establish the Bay TMDL and the allocations for the major basins in each jurisdiction. The Watershed Model produces an estimate of the real world benefits of BMPs imple-

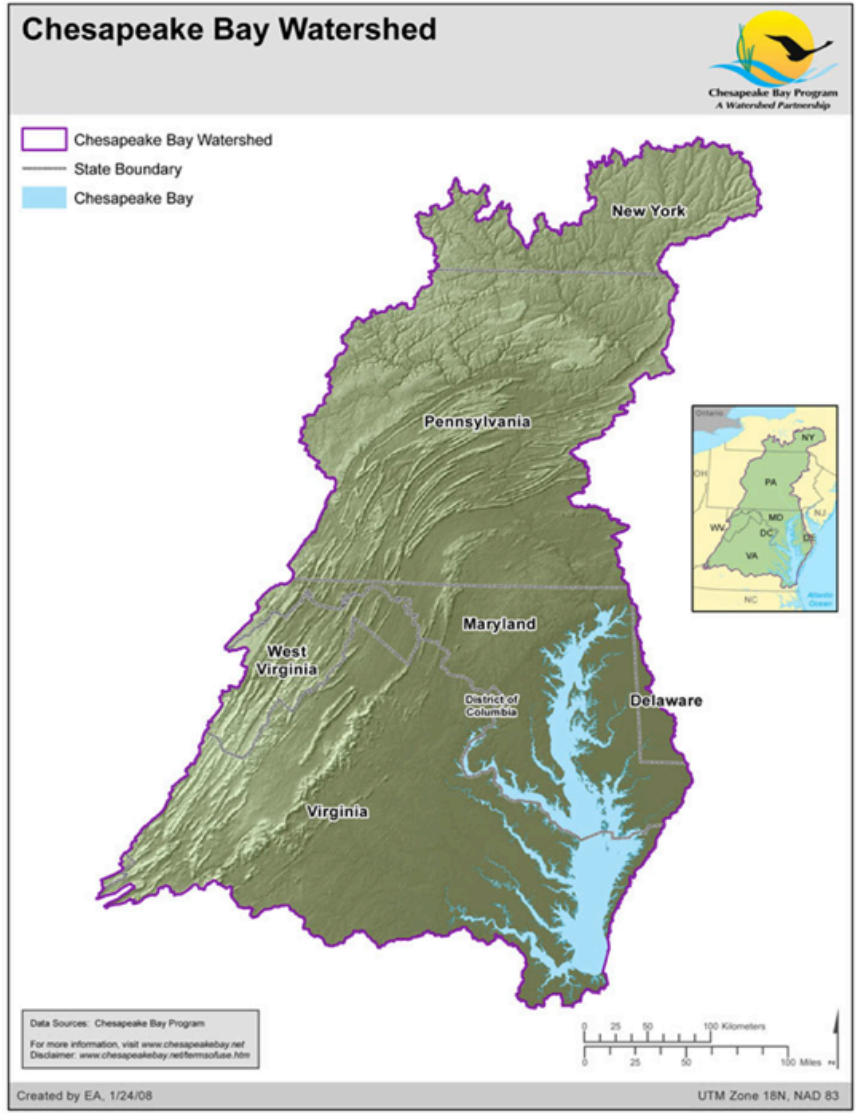

Figure 1 Chesapeake Bay watershed and major jurisdictional boundaries.

Devereux, O. and J.R. Rigelman. 2014. "CAST: An Online Tool for Facilitating Local Involvement in Watershed Implementation Plans for the Chesapeake Bay Total Maximum Daily Load." Journal of Water Management Modeling C364. doi: 10.14796/JWMM.C364.

(c) CHI 2014 www.chijournal.org ISSN: 2292-6062 
mented within the watershed. The Watershed Model is used to evaluate WIPs, create 2 y milestones and track the implementation of BMPs. The Watershed Model is used to predict nitrogen, phosphorus and suspended solid loads under various management scenarios. Ultimately it is the Watershed Model that estimates if the actions of the jurisdictions are meeting the limits under the Bay TMDL. This is because the Watershed Model estimates the impact of the BMPs as if the BMPs were in place for an average 10 y period. Thus the TMDL requires the BMPs to be implemented by the year 2025, but the USEPA does not expect the BMPs to have achieved full effectiveness by 2025 . For example, it takes time for forest buffers to grow and meet their full pollutant removal capacity. Reducing nutrient applications in farmland has an immediate effect, but there are also lag times associated with nitrogen stored in groundwater. Reducing erosion on the land is critical, but there will still be slugs of sediment that are already stored in streams that will continue to move.

Inputs to the Watershed Model are created using the Nutrient and Sediment Scenario Builder (USEPA 2009). While running the Watershed Model takes $\sim 5 \mathrm{~h}$, and running Scenario Builder takes $\sim 1 \mathrm{~h}$, compiling data and making sure it is validated can take several days for technical staff. It is impractical for local or state jurisdictions to submit many scenarios for model runs to determine if a particular plan is achieving targets, yet there is no other way for jurisdictions to ascertain they were meeting targeted loads.

For these reasons, we developed an approximation of the Watershed Model output for use by local jurisdictions and other planners, to predict the nitrogen, phosphorus and suspended solid loads that are simulated by the Watershed Model. The Chesapeake Assessment Scenario Tool (CAST) is an online nutrient and sediment load estimator that streamlines and facilitates WIP and milestone preparation consistent with the Bay TMDL (Devereux and Rigelman 2011). CAST is free and available online to the public at http://casttool.org/. CAST does not require users to download any special software. Anyone may create a login id and use the tool.

The objective was to build a simulation model with a transparent architecture that produces two products: estimates of nitrogen, phosphorus and sediment load reductions using a variety of BMPs; and inputs to the Chesapeake Bay Program's Scenario Builder. Figure 2 illustrates the suite of models, their inputs, and how they work in concert.

CAST builds on the science that went into the development of the Watershed Model by providing a broadly accessible online tool to facilitate efficient management decision making and greater environmental protection. CAST approximates loads using similar logic, rules and assumptions to the Watershed Model. This ensures consistency with the TMDL: CAST's predicted loads are comparable to the Watershed Model. However, CAST does not run the Watershed Model, but rather approximates that model's output for rapid online scenario development. The urban land use approximations are calculated using a similar methodology to the Chesapeake Bay Program's suite of models. Agricultural land uses are modeled in CAST using linear equations, with coefficients generated from Watershed Model data using factorial inputs over combinations of BMPs and land use change. Loads are estimated for each land use and each modeling segment.

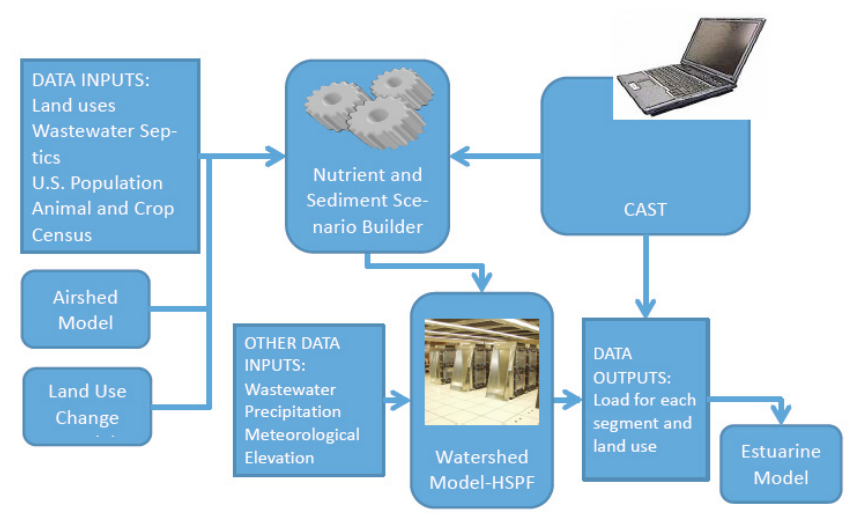

Figure 2 Suite of Chesapeake Bay Program models and inputs that are used for the Bay TMDL.

CAST facilitates an iterative process to determine if TMDL allocations are met. Because CAST is online and easy to use, local planners may deeply engage, thereby improving local management decisions and securing a higher likelihood of actual implementation (Mullinix et al. 2009). CAST allows users to select the geographical area for their plan and to identify the level of implementation of various BMPs. CAST outputs predict pollutant loads and these are compared against allocations. Local planners can compare among different scenarios that they create, so they can determine which scenario meets the allocation and is politically feasible. In this way, planners can develop multiple options rapidly (Antos and Devereux 2009). Each local jurisdiction that uses CAST uses the same methodology, which ensures the ability to replicate results. CAST also automatically creates inputs to the Chesapeake Bay Program's models that pass validation, saving time and effort for Chesapeake Bay Program staff. While CAST was first developed in 2010 to provide local jurisdictions, such as counties, with a tool to provide input into the Bay TMDL WIP development, the functionality of CAST subsequently has been expanded to serve multiple needs for environmental planning in the Chesapeake Bay watershed.

The following sections describe the methodology for developing CAST and its use by the jurisdictions.

\section{Methodology}

\subsection{Data Used in Modeling BMPs}

CAST must have a data set with an initial load for every land use in every modeling segment. There are 377 land segments and 1084 river segments modeled for Chesapeake Bay. CAST must have an initial load for each land use and modeling segment even where that land use may not currently exist in that modeling seg- 
ment. This is necessary to accommodate the BMPs that can create or eliminate certain land uses. For example, the Tree Planting BMP converts the initial land use to forest. To accurately model a scenario with the Tree Planting BMP, CAST needs to have a forest load in that segment.

To generate the data set with a load for every land use in every segment, the current land use with no BMPs was adjusted so that there was a portion of each land use taken from an existing land use. This scenario was run through the Watershed Model. This initial load may not be changed by the user, although the land use can be changed using land use change BMPs. This scenario provided the loads, but the land use that CAST uses are those established for each year by the Chesapeake Bay Program Partnership.

The intersection of the land and river segments is the modeling scale for both CAST and the Watershed Model. There are 31 land uses and the Watershed Model runs a simulation for $20 \mathrm{y}$. Loads are calculated in CAST and in the Watershed Model for both edge-of-stream (EOS) and the load delivered to Chesapeake Bay (DEL). There are constant delivery factors that convert the edge-of-stream loads to delivered loads. Management actions like BMPs do not change the constant delivery factors. All loads are calculated for each acre, and then multiplied by the total land area in the segment.

Once the initial loads have been established, reductions from BMPs are calculated. The Chesapeake Bay Program partnership relies upon a process of convening expert panels to evaluate BMP effectiveness for a range of BMPs that are being implemented in Chesapeake Bay watershed jurisdictions. The process is based on a uniform set of guidelines and criteria and a rigorous scientific process initially developed and set forth in a 2009 report by Simpson and Weammert. Since then, the Protocol for Development, Review and Approval of Loading and Effectiveness Estimates for Nutrient and Sediment Controls in the Chesapeake Bay Watershed Model was developed for establishing and modifying BMPs and their effectiveness values (CBP 2010). This protocol requires involvement by experts and members of the Chesapeake Bay Program partnership. The approach references small watershed monitoring studies and was designed to remove unwarranted optimism in the research values relative to real-world implementation. The approach used in establishing BMP effectiveness was designed to arrive at BMP effectiveness values that were unbiased and realistic. As of January 2013, the Chesapeake Bay Program partnership has approved >130 BMPs for use in the Bay watershed and has established effectiveness values for nitrogen, sediment, and phosphorus for those BMPs, as applicable. All of these BMPs also are available in CAST.

Some BMPs change the land use while other BMPs use an effectiveness value. Yet another type reduces the load delivered or the application of nutrients. Each of these is described in turn. BMP effectiveness values express the percent pollutant reduction achieved by implementing a particular BMP compared to the load that would have been delivered before BMP implementation.

\section{Effectiveness Values}

An effectiveness value is the percentage of a pollutant that is removed when the BMP is applied. For example, the Dry Extended Detention Ponds BMP removes $20 \%$ of nitrogen that would have been delivered without the detention ponds. When a pass-through value for a BMP is referred to, it is simply $100 \%$ minus the effectiveness value. In this case, the pass-through value for dry extended detention ponds is $80 \%$.

\section{Land Use Change}

Land use change BMPs simply change one land use to another. For example, the Urban Growth Reduction BMP changes an urban land use to agricultural and forest land in the proportion that agricultural and forest land exists in the geographic area. Another example is the Urban Forest Buffers BMP that converts urban land uses to a forest land use.

\section{Land Use Changes With Effectiveness Values}

Some BMPs work as both land use change and effectiveness value BMPs. In these cases, the land use change is calculated first, and then an effectiveness value is applied to an additional number of acres of the original land use. The urban land use change BMP that also has an effectiveness value is the Forest Buffers BMP. It is assumed that the presence of this BMP reduces the amount of nutrients delivered from upland areas as water and nutrients move through the soil matrix. When a BMP is applied to a specific land use, the benefit of the effectiveness value is applied to all land uses within that group. For example, if it is applied to regulated pervious developed, the effectiveness value is credited to all urban land uses even though only the regulated pervious developed is converted to the new land use. The urban land use change BMP that has the effectiveness value applies the effectiveness value to the same area of land as was converted.

\section{Load Reduction}

There are a few special BMPs that do not fit among the three categories of land use change, effectiveness, or land use and effectiveness BMPs. These are load reduction BMPs and those that can be applied to urban land include Stream Restoration, Dirt and Gravel Roads, and Street Sweeping.

BMPs are calculated in a specified sequence. While the CAST user may add BMPs in any order, this does not affect the sequence of BMP calculations. To understand the calculation sequence of BMPs, it is simplest to consider that each BMP is a member of a group. For example, one group of stormwater BMPs includes Dry Ponds, Extended Detention Dry Ponds, Bioswales, and other similar BMPs. Urban Nutrient Management is in a different group. Street Sweeping is in yet another group. Within each group, there may be more than one BMP. There is a specified sequence for each group and for each BMP within a group. This grouping allows there to be some BMPs that are mutually exclusive with other BMPs. In the example of the group that includes Extended Detention Dry Ponds and Bioswales, only one of those two BMPs may be credited on the same acre of land. The BMP 
sequence also is necessary because it is possible for CAST users to apply more BMPs than there is area available to be treated. When this happens, the BMPs later in the sequence are cut off and not credited.

Land use change BMPs are always calculated before any other BMP type and those BMPs on urban land uses follow this specific order:

1. Urban growth reduction;

2. Impervious urban surface reduction;

3. Forest conservation;

4. Urban forest buffers;

5. Urban grass buffers;

6. Urban tree planting, urban tree canopy; and

7. Abandoned mine reclamation.

After land use change BMPs are calculated, effectiveness value BMPs are calculated. They also are grouped and follow a specific sequence. For example, the Forest Buffers BMP has a land use change and effectiveness value. The Grass Buffers BMP is only a land use change BMP. The Forest Buffer BMP is applied earlier than the Grass Buffer BMP in the calculation sequence. When a user can decide to steer resources toward implementing either grass buffers or forest buffers, it would produce a greater load reduction to implement forest buffers because forest buffers provide both a land use change and an effectiveness value reduction.

In addition to considering the BMP type and sequence, CAST users are advised to consider whether a BMP is mutually exclusive to or is assumed to overlap with other BMPs. BMPs that can exist on the same acre of land are assumed to have some overlap. This overlap essentially reduces the combined effectiveness of those BMPs. This is shown in the calculation steps in the following section. The Chesapeake Bay Program refers to overlapping BMPs as multiplicative. This type of BMP is considered to behave as consecutive BMPs, such as in a treatment train. One BMP reduces the pollutants available for subsequent $B M P s$ to reduce. BMPs in different groups may overlap. BMPs in the same group may not overlap. For example, Street Sweeping, Dry Ponds, and Urban Nutrient Management can all treat the same acre of land.

BMPs that do not overlap are mutually exclusive. Mutually exclusive BMPs are those that cannot exist on the same acre of land. BMPs are mutually exclusive when they are land use change BMPs and there is more than one member in a group. For example, Streambank Protection With Fencing cannot exist on the same acre as Streambank Protection Without Fencing. The Chesapeake Bay Program refers to this type of BMP as additive.

All land use change BMPs are mutually exclusive. For BMPs that are both land use change and effectiveness value BMPs, first the land use change is credited; next the effectiveness is credited to the appropriate number of acres and land use. The BMPs are listed in the table of BMP groups and sequence twice, once for the land use change and again for the effectiveness value.

Table 1 shows the group order and sequence within group. The group order and sequence within the group indicate the order in which the BMPs are calculated. The calculations following will elucidate this point.

Table 1 Example of BMP groups and sequence of calculation (the table only shows a few BMPs because of space limitations; the complete table may be found at http:// casttool.org/include/App5.xls).

\begin{tabular}{|c|c|c|c|c|}
\hline BMP & BMP Tyре & BMP Group Name & $\begin{array}{l}\text { BMP } \\
\text { Group } \\
\text { Order }\end{array}$ & $\begin{array}{l}\text { Sequence } \\
\text { within } \\
\text { Group }\end{array}$ \\
\hline Urban Growth Reduction & $\begin{array}{l}\text { Land use } \\
\text { change }\end{array}$ & $\begin{array}{l}\text { Urban growth } \\
\text { reduction }\end{array}$ & 1 & 1 \\
\hline $\begin{array}{l}\text { Impervious Urban Surface } \\
\text { Reduction }\end{array}$ & $\begin{array}{l}\text { Land use } \\
\text { change }\end{array}$ & $\begin{array}{l}\text { Impervious surface } \\
\text { reduction }\end{array}$ & 2 & 1 \\
\hline$[\ldots]$ & {$[\ldots]$} & {$[\ldots]$} & {$[\ldots]$} & {$[\ldots]$} \\
\hline Urban Forest Buffers & $\begin{array}{l}\text { Effectiveness } \\
\text { value }\end{array}$ & Urban forest buffers eff & 28 & 1 \\
\hline$[\ldots]$ & {$[\ldots]$} & {$[\ldots]$} & {$[\ldots]$} & {$[\ldots]$} \\
\hline $\begin{array}{l}\text { Stormwater to the Maximum } \\
\text { Extent Practicable (SW to the MEP) }\end{array}$ & $\begin{array}{l}\text { Effectiveness } \\
\text { value }\end{array}$ & $\begin{array}{l}\text { Stormwater manage- } \\
\text { ment }\end{array}$ & 43 & 1 \\
\hline Wet Ponds and Wetlands & $\begin{array}{l}\text { Effectiveness } \\
\text { value }\end{array}$ & $\begin{array}{l}\text { Stormwater manage- } \\
\text { ment }\end{array}$ & 43 & 2 \\
\hline $\begin{array}{l}\text { Dry Detention Ponds and Hydro- } \\
\text { dynamic Structures }\end{array}$ & $\begin{array}{l}\text { Effectiveness } \\
\text { value }\end{array}$ & $\begin{array}{l}\text { Stormwater manage- } \\
\text { ment }\end{array}$ & 43 & 3 \\
\hline Dry Extended Detention Ponds & $\begin{array}{l}\text { Effectiveness } \\
\text { value }\end{array}$ & $\begin{array}{l}\text { Stormwater manage- } \\
\text { ment }\end{array}$ & 43 & 4 \\
\hline $\begin{array}{l}\text { Urban Infiltration Practices } \\
\text { Without Sand, Veg. - A/B Soils, No } \\
\text { Underdrain }\end{array}$ & $\begin{array}{l}\text { Effectiveness } \\
\text { value }\end{array}$ & $\begin{array}{l}\text { Stormwater manage- } \\
\text { ment }\end{array}$ & 43 & 5 \\
\hline $\begin{array}{l}\text { Urban Infiltration Practices } \\
\text { With Sand, Veg. - A/B Soils, No } \\
\text { Underdrain }\end{array}$ & $\begin{array}{l}\text { Effectiveness } \\
\text { value }\end{array}$ & $\begin{array}{l}\text { Stormwater manage- } \\
\text { ment }\end{array}$ & 43 & 6 \\
\hline
\end{tabular}

\subsection{BMP Calculation Steps}

There are five steps used to calculate the loads that vary under differing BMP inputs:

1. Determine BMP 2007 percentage of land (Equation 1);

2. Verify acres available;

3. BMP pass-through value (Equation 2);

4. Overall pass-through value (Equation 3); and

5. Overall BMP reduction (Equation 4).

These calculations are performed by CAST, and are invisible to the user. This allows planners without any modeling background to establish effective plans. The following describes each step and provides examples.

\section{Step 1: Determine BMP 2007 percentage of land}

The first step in calculating the load reduction is to verify that certain BMPs submitted are greater than those submitted in 2007. This rule applies to the following urban BMPs:

- Abandoned Mine Reclamation;

- Forest Conservation;

- Impervious Urban Surface Reduction;

Urban Forest Buffers; 
- Urban Grass Buffers; and

- Urban Tree Planting, Urban Tree Canopy.

The base land use is 2010 , the year that the Bay TMDL was established (USEPA 2010). Since 2010 includes land use change BMPs from prior years, 2007 is used as a baseline for minimum BMP implementation. The purpose of this rule is to verify that only increases in land use change BMPs beyond 2007 levels are counted, not decreasing levels of BMPs.

While it is logical to consider that 2010 is a projection and should include land use change, and therefore no credit should be given for any land use change BMPs made prior to 2010, this is not the way the Chesapeake Bay Program handles the calculation. Since CAST is designed to mirror the results of the Chesapeake Bay Program models, CAST calculations include the following equation to address land use change since 2007.

Your scenario BMP \% land > 2007 progress

scenario \% land

Examples 1 and 2 illustrate the use of Equation 1.

Example 1 Land use change since 2007.

Abandoned mine reclamation
2007: 40 acres
2010: 10 acres
No credit given because acres in 2010 are not $>2007$

Example 2 Land use change since 2007.

Abandoned mine reclamation
2007: 35 acres
2010: 45 acres
Credit given for 10 acres, because $2010-2007=10$
Credit only given for difference.

\section{Step 2: Verify Acres Available}

The second step in calculating the load reduction is to verify that there are adequate acres for each BMP. If there are not enough acres to accommodate the BMPs, then those BMPs later in the sequence will only be applied to the available acres. It is possible for the user to specify a BMP for more acres than are available.

For example, there are multiple members of the Stormwater BMP group. Whenever there is more than one member of a group, the BMPs are necessarily mutually exclusive. Since wet ponds are mutually exclusive with dry ponds, the acres available for wet ponds are only those that remain after dry ponds are calculated. If there are a total of 100 acres, and the user specifies $95 \%$ of the acres are in wet ponds and $45 \%$ of the acres are in dry ponds, then CAST will return 95 acres in wet ponds and 5 acres in dry ponds. The full $45 \%$ of dry ponds was not credited because there were not enough available acres after the wet ponds were calculated. Thus, the user must consider the BMP groups and the order within groups to optimize reductions. This illustration is summarized in Example 3.
CAST provides multiple tables to download and print. To verify that acres were credited as expected, users can download the BMPs Submitted vs Credited table from the Summary page to compare the amount of acres calculated from the submitted information with the amount of acres credited.

Example 3 Mutually exclusive BMPs.

Total acres $=100$
User input:
Wet ponds $=95 \%$; Dry ponds $=45 \%$
Model Calculates:
Wet ponds acres treated: $95 \% * 100=95$
Minimum of the user input or amount remaining after the previous BMP: Min $((45 \% * 100)$,
$\quad(100-95))$
The minimum in this case is what remains after the previous BMP: $100-95=5$
Result:
Wet ponds acres treated $=95$; Dry ponds acres treated $=5$

\section{Step 3: BMP Pass-Through Value}

BMPs are calculated by land use for each segment for each pollutant. CAST calculates a single pass-through factor for BMPs in each group. A pass-through factor is simply the amount of pollutant that is not removed by the effectiveness value.

A single pass-through factor $F_{g}$ is calculated for all the BMPs in a group using the following formula. This same formula also is used even where there is only one BMP in a group. The calculation is shown in Equation 2.

$$
\begin{aligned}
& \text { For each BMP group } g(g=1,2, \ldots, G), \\
& F_{g}=1-\sum_{B M P=1}^{n}\left(\frac{i}{t} * E_{B M P}\right)
\end{aligned}
$$

where:

$$
\begin{aligned}
B M P & =\text { a specific BMP, } \\
g & =\text { BMP group, } \\
G & =\text { total number of BMP groups, } \\
F & =\text { pass-through factor, } \\
n & =\text { total number of BMPs in the group, } \\
i & =\text { implementation acres, } \\
t & =\text { total acres available, and } \\
E & =\text { effectiveness value. }
\end{aligned}
$$

\section{Step 4: Overall Pass-Through Value}

An overall pass-through factor $F_{O}$ is calculated by multiplying the pass-throughs for each group. The result will necessarily be $\leq 1$; if $=1$, all pollutants pass through and there are no BMP reductions.

$$
F_{O}=\prod_{g=1}^{G} F_{g} \leq 1
$$

\section{Step 5: Overall BMP Reduction}

If it is more intuitive to consider this in terms of the overall reduction then convert the overall pass-through factor to an overall $\mathrm{BMP}$ reduction fraction, $E_{O^{\prime}}$ by:

$$
E_{O}=1-F_{O}
$$


where:

$E_{0}=$ overall effectiveness value, and

$F_{0}=$ overall pass-through factor.

There is an overall reduction effectiveness value calculated for each land use and segment and pollutant.

Example 4 BMP calculation.

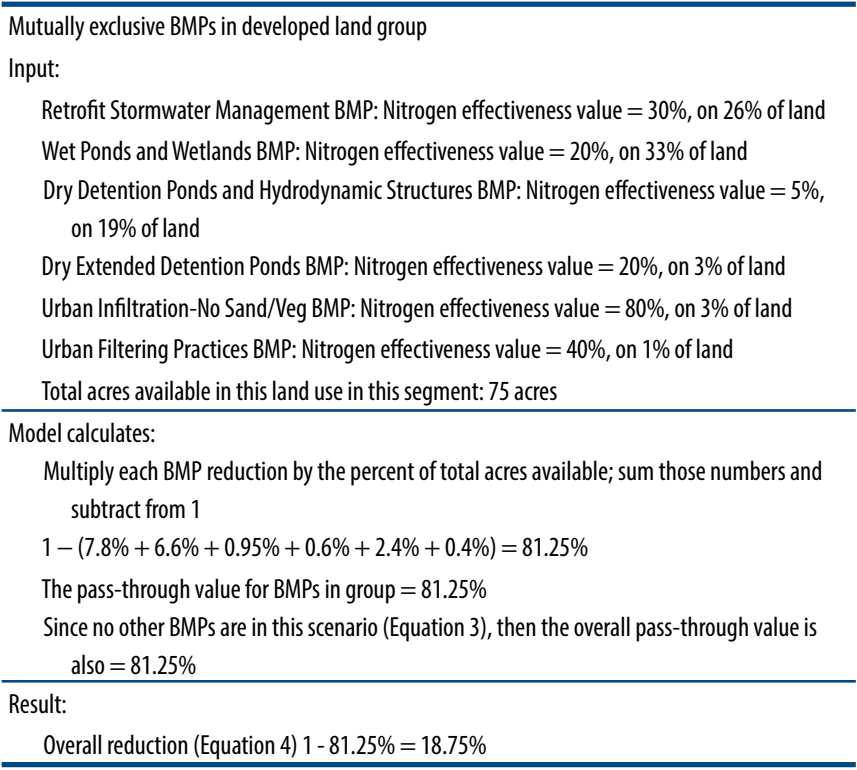

\subsection{Method for Using BMP Calculations in CAST}

In CAST, the user can begin with a scenario without BMPs, or copy BMPs from another scenario. The land use in CAST is adjusted based on the user-entered BMPs. Next, the BMP load reduction in CAST is applied as described above. This is a similar method to that used by the Chesapeake Bay Program models. The pollutant load for each acre is calculated and multiplied by the post-BMP land use. CAST output shows both the edge of stream loads and load delivered to the Bay.

\subsection{Outputs}

CAST estimates of load reductions for point and nonpoint sources include: agriculture, urban, waste water, forest, and septic loading to the land (edge-of-stream) and loads delivered to Chesapeake Bay. CAST stores data associated with each BMP as well as the load for each sector and land use. With these data tables, CAST also serves as a data management system. Thus users may quantify the impacts of various management actions while improving local management decisions.

In addition, CAST creates data files for direct input to the CBP's models, avoiding the need to transform or transpose such data and eliminating a potential source of error. CAST and other Chesapeake Bay modeling tools complement each other.

\section{Using CAST}

CAST users designate a specific set of BMPs on Watershed Model segments. CAST is designed for broad scale planning. CAST is not intended to be used to develop site-specific designs.

Data is entered into CAST in the sequence outlined in Figure 3. After logging in, users may add a new scenario, edit an existing scenario, or compare among existing scenarios. There is another scenario page with more details about each scenario. Following the two scenario pages, there is a dropdown menu for entering the categories of BMPs with >100 BMPs. Users may move among the pages in any order desired. There is a summary page with the results of the scenario and links to download data. Lastly, there is the ability to compare pollutant loads among scenarios. Comparisons among scenarios are useful for assessing if particular scenarios meet a target. By viewing the land use loads, users can determine if the load allocation was met.

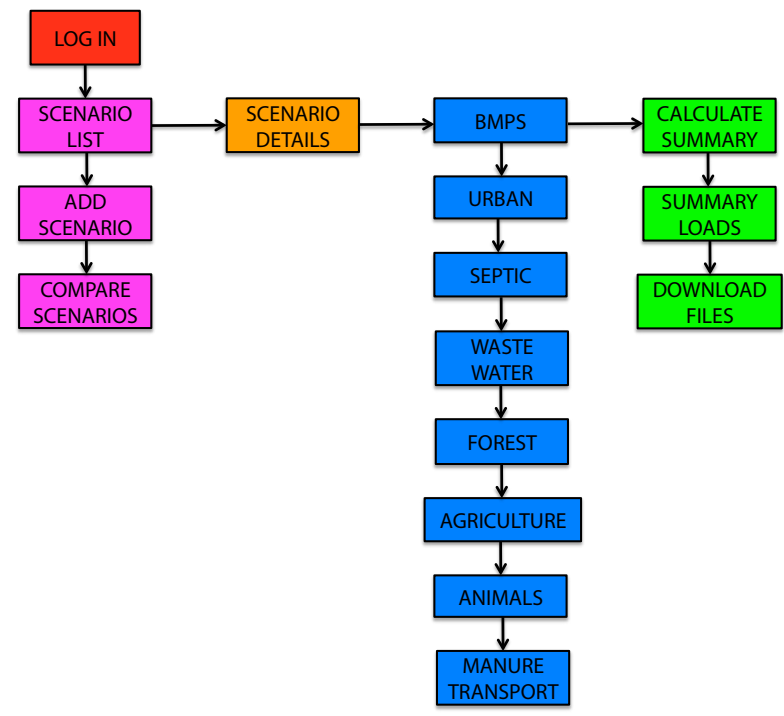

Figure 3 Scenario creation steps in CAST.

CAST stores data associated with each BMP as well as shows the load for each sector and land use. With these data tables, CAST can serve as a data management system.

\section{Results and Discussion}

CAST has been used by many local jurisdictions and states for the Phase 1 and Phase 2 WIPs, 2012 Milestones, and even local TMDLs. Any user may see the source of the data that was used in developing the TMDL and the state's most recent annual progress scenario and WIP. This transparency allows the involvement of the counties and other local planners in the state WIP. CAST is easily accessible online with no need to install specific databases or software. All who request a login are granted one. This transparency has led to greater involvement and buy-in to the Bay TMDL.

CAST allows users to understand which BMPs provide the greatest load reduction benefit and the extent to which these 
BMPs can be implemented. Based on the scenario outputs, users can refine their BMP choices in their planning. Jurisdictions learned that the model is more sensitive to some BMPs than others. This led to changes in implementation. For example, mowed grass buffers are not considered particularly effective. Jurisdictions that previously implemented grass buffers shifted their implementation to other, more effective BMPs. Jurisdictions also learned that the model is sensitive to the location of BMPs. By seeing the variation in delivery factors, jurisdictions targeted BMPs to those locations where they have the most impact.

Using multiple models strengthens all models. Comparisons between CAST and the Watershed Model led to corrections and improvements in the Watershed Model.

\subsection{CAST Validation}

Validation of a CAST scenario was performed with the BMPs implemented as of June 30, 2011. Alternatives scenarios for validation could have included only one or two BMPs, or a scenario where BMPs were implemented at a level to simulate what would occur if everyone does everything, everywhere, to reduce loads. However, we assumed most CAST users would run scenarios that were incrementally more than what presently was implemented, so we used the current level of implementation for validation.

Results showed that agreement for urban land uses was within $\pm 1 \%$. These differences were due to rounding error related to the way the rounding is defined in FORTRAN for the Watershed Model. For all land uses, the agreement was within $10 \%$ of the Watershed Model loads in 95\% of the modeling segments. The error was predominantly on agricultural land uses in small number of land-river segments. This high level of agreement with the Watershed Model indicates that CAST is a valuable and useful tool for rapid assessment of load reductions given varying BMP inputs. See Table 2.

Table 2 Validation results showing the percentage of counties by land use that are within $10 \%$ of the watershed (model output for urban, agriculture and forest source sectors).

\begin{tabular}{lc}
\hline & $\pm 10 \%$ of Watershed Model output by land use and \\
& county \\
\hline Acres per land use & $99.82 \%$ \\
Total nitrogen edge-of-stream & $95.68 \%$ \\
Total phosphorus edge-of-stream & $97.94 \%$ \\
Total suspended solids edge-of-stream & $99.93 \%$ \\
\hline
\end{tabular}

There is no one BMP that had more error than another BMP. This is because the BMPs work in concert with each other as defined earlier in the discussion of BMP type (land use or effectiveness value), groups (overlapping vs mutually exclusive), and sequence. A load change cannot be attributed to a single BMP since one affects another.

Prediction of BMP effectiveness in both CAST and the Watershed Model require confirmation from field experience and monitoring. Several factors may affect BMP effectiveness, including operational conditions, implementation date and time to maturity, and variation in natural conditions such as heterogeneity in soils, topography, and management. Each of these types of uncertainty was taken into account when expert teams coordinated by the Chesapeake Bay Program partnership established BMP effectiveness values for use in the Watershed Model (Simpson and Weammert 2009). BMPs and their effectiveness values are periodically reviewed and modified using a protocol that requires involvement by experts and members of the partnership (CBP 2010). The Protocol specifies that the most recent research literature should be considered in establishing and revising BMP effectiveness. Moreover, the Watershed Model was calibrated against in 2010 using > 285 stream monitoring stations. This calibration included the BMPs that were installed. The calibration procedure in the Watershed Model assures that predicted loads match closely with the monitoring data. While not a direct measurement of an individual BMP's impact, the Watershed Model calibration is an indicator of overall agreement.

\section{Conclusions}

CAST improves local pollutant and land management decisions by facilitating involvement in addressing the Bay TMDL by local planners. Local planners use CAST to predict loads for the USEPArequired WIPs and 2 y milestones. While CAST was developed to assist jurisdictions with their WIP planning, it is the decision of each jurisdiction to determine how and for what purpose each jurisdiction uses CAST. Local jurisdictions have used CAST to determine which BMPs generate the most load reductions in their local geographical area. Some counties have refocused their BMP implementation to specific areas where the loads may be reduced with fewer and less expensive BMPs. Some states required counties to use CAST for developing pollutant load plans, and then merged together the county scenarios for a state-wide scenario. This method of developing a state-wide scenario would not have been possible without CAST.

Since CAST is based on the same model used to determine the TMDL and the allocations, it has internal consistency for loads, geographical scale and sectors. There is a multitude of tools available, but these other tools have assumptions that may be different from those used in developing the Bay TMDL. Since jurisdictions are held accountable to the loads calculated by the Watershed Model, it is critical that planning tools have the same sensitivities and loads. CAST produces loads for urban land uses within $1 \%$ of the Watershed Model loads. This is because CAST uses CBP approved BMPs and efficiencies and maintains consistency with the CBP Phase 5.3.2 Watershed Model and updates.

Future enhancements to CAST are to be developed with input from the states and local jurisdictions, the Chesapeake Bay Program, and the USEPA. CAST continues to evolve to meet the needs of users. 


\section{Acknowledgments}

CAST was originally developed under a grant from the Maryland Department of the Environment. Continued funding is provided by the USEPA Chesapeake Bay Program and Virginia Department of Conservation and Recreation.

\section{References}

Antos, K. and O. H. Devereux. 2009. “Building Bridges Between Land Use Planning and Regional Water Quality." Environmental Planning Journal 20 (1): 14-18.

CBP (Chesapeake Bay Program Water Quality Goal Implementation Team). 2010. Protocol for Development, Review, and Approval of Loading and Effectiveness Estimates for Nutrient and Sediment Controls in the Chesapeake Bay Watershed Model. http://www.chesapeakebay.net/channel_files/19491/ nutrient-sediment_control_review_protocol_with_addendums_05092013.pdf.

Devereux, O. H. and J. R. Rigelman. 2011. Chesapeake Assessment and Scenario Tool General Features and User's Guide. http:// casttool.org/include/CASTUsersGuide.pdf.

Mullinix, C., S. Phillips, K. Shenk, P. Hearn and O. H. Devereux. 2009. "Facilitating Adaptive Management in the Chesapeake Bay

Olivia H. Devereux Devereux Environmental Consulting, Inc., Silver Spring, MD.

Jessica R. Rigelman J7 LLC, Annapolis, MD.
Watershed Through the Use of On-Line Decision Support Tools." In Planning for an Uncertain Future-Monitoring, Integration and Adaptation, edited by R. M. T. Webb and D. J. Semmens. U.S. Geological Survey Scientific Investigations Report 2009-5049. Washington, DC: U.S. Geological Survey.

Simpson, T. and S. Weammert. 2009. Developing Best Management Practice Definitions and Effectiveness Estimates for Nitrogen, Phosphorus and Sediment in the Chesapeake Bay Watershed. http://archive.chesapeakebay.net/pubs/BMP_ASSESSMENT_REPORT.pdf.

USEPA. 2009. Estimates of County-Level Nitrogen and Phosphorus Data for Use in Modeling Pollutant Reduction. Washington, DC: U. S. Environmental Protection Agency. Documentation for Scenario Builder Version 2.4., revised 2012.

USEPA. 2010. Chesapeake Bay Total Maximum Daily Load for Nitrogen, Phosphorus and Sediment. Washington, DC: U. S. Environmental Protection Agency.

USEPA. 2011. Guide for Chesapeake Bay Jurisdictions for the Development of Phase II Watershed Implementation Plans. Washington, DC: U. S. Environmental Protection Agency. 